\title{
Pork loin two-toning and drip loss in relation to steak cross-section anatomical position, plasma and exudate glucose
}

\author{
Patricia Maloso Ramos, Eduardo Francisquine Delgado*
}

University of São Paulo/ESALQ - Dept. of Animal Science, Av. Pádua Dias 11 - 13418-900 - Piracicaba, São Paulo Brazil.

*Corresponding author <efdelgad@usp.br>

Edited by: Concepta Margaret McManus Pimentel

\begin{abstract}
Perception of color and its relationship to water holding capacity are important for defining the yield and quality of the pork production process. The aim of this study was to identify the relationship among color measurements taken at various anatomical positions in the cross-sectional surface of pork loin steak, and measurements of fluid exudation and its glucose concentration, as well as the impact on these attributes due to plasma glucose at slaughter. Two assays were conducted sequentially: i) investigation of the surface color parameters at different anatomical positions in the pork loin cross-section and their relationship to general exudation; and ii) the effect of plasma glucose levels on surface color variables, drip loss and glucose exudate concentration in three anatomical regions in the steak. The $L^{*}$ value of the ventro-lateral region, in the first assay, had the highest correlation with average steak drip loss at all anatomical points, exudation increasing proportionally between 48 and $72 \mathrm{~h}$. The hue angle was also positively correlated with drip loss and lightness. The drip loss was greater when the animals had high plasma glucose, especially in the intermediate and lateral regions of the steak surface. The intermediate region presented greater lightness and lower redness. The plasma and glucose exudate concentrations, potential indicators of the muscle glycolytic metabolism, were related to color and drip loss. These variables can be influenced by the anatomical region inside the muscle, impacting the ability to retain water, two-toning occurrence and overall pork loin quality. Keywords: Longissimus dorsi, color, glycolytic metabolism, quality
\end{abstract}

Received September 03, 2013

Accepted February 27, 2014 with higher occurrence of glycolytic fibers (Choe et al., 2009).

Pork loin steak can have surface color and water holding capacity problems. Pale, soft and exudative or normal color (Reddish-pink), soft and exudative (RSE) are two common occurrences in pork (Warner et al., 1997). One possible way to indirectly and easily predict water holding capacity problems associated with visual color appraisal is to analyse surface color parameter readings. Some of the color parameters represented by lightness $\left(\mathrm{L}^{*}\right)$, redness $\left(\mathrm{a}^{*}\right)$, yellowness $\left(\mathrm{b}^{*}\right)$ and the composition of these parameters in terms of hue angle and chroma are highly correlated with the visual perception of pink intensity (Brewer et al., 2001) and are linked to excessive water losses (Mancini and Hunt, 2005). The aim of this study was to verify the impact of plasma glucose at slaughter on various anatomical positions of pork loin steaks, color and drip losses.

\section{Materials and Methods}

The study was conducted through two complementary assays. The first assay aimed to identify the toning non-uniformity and its relationship with drip loss by sampling from a local retail store. The second assay had meat sampled from an experimental abattoir and it aimed to verify the impact of plasma glycemia on color and water holding capacity in different anatomical regions on the surface of pork loin steaks. The assays were conducted separately and successively. 


\section{Assay 1}

Samples: nineteen randomly selected pork loin samples with a thickness of $2.5 \mathrm{~cm}$, taken from between the eighth and eleventh ribs, obtained 24-36 h post-mortem from right carcasses were acquired at a retail store. The steaks were refrigerated and transported to a meat laboratory for analysis.

Color measurements: the objective measures of color followed the CIELab standards as represented by $\mathrm{L}^{*}$ (lightness), $a^{*}$ (redness) and $b^{*}$ (yellowness) at different points at steak surface (Figure 1) using a colorimeter (Minolta CR 400) with $0.8 \mathrm{~cm}$ aperture, calibrated for illuminant $\mathrm{C}$ and $\mathrm{a} 2^{\circ}$ angle. The time lapse to reading was between 1 and $2 \mathrm{~h}$ after steak exposure to oxygen at room temperature of $21^{\circ} \mathrm{C}$. The values for Chroma (C) and Hue angle $(\mathrm{H})$ (Brewer et al., 2001) were calculated according to the following formula: $\mathrm{C}=\sqrt{ }\left(\left(\mathrm{a}^{*}\right)^{2}+\left(\mathrm{b}^{*}\right)^{2}\right)$ and $\mathrm{H}=\operatorname{arctangent}\left(\mathrm{b}^{*} / \mathrm{a}^{*}\right)$, respectively. For those samples that had shown non-uniform colorimeter readings in the Longissimus thoracis positions within the cross sectional surface were called two-toning steaks, even though the two toning term is mainly related to color differences between muscles within a cut.

Exudate absorption by filter paper: filter paper cylinders with a diameter of $2.5 \mathrm{~cm}$ were positioned at close contact to the steak surface at the medial position (Kauffman et al., 1998) to measure the fluid exudation. After 20 min or until one of them was completely impregnated with absorbed liquid, the cylinders were taken off in the same order that they were put on each steak. The results are expressed in differences between the filter paper weight before and after exudate absorption.

Drip loss: measured for each standardized steak (100 g, without fat and/or connective tissue) that was placed on

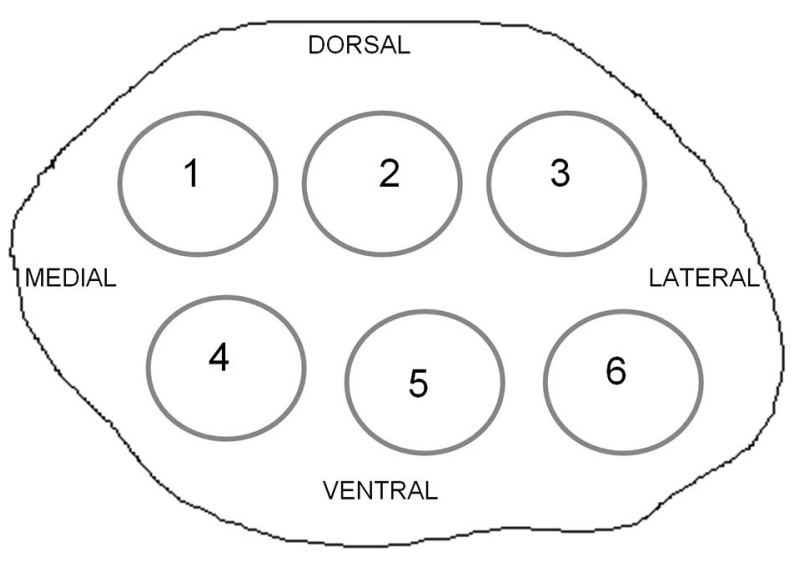

Figure 1 - Scheme illustrating the anatomical positions in the steak (cross Longissimus) for objective measurement of color. a reticulated plastic net inside a plastic package (Honikel and Hamm, 1994). This material was kept under refrigeration at $4{ }^{\circ} \mathrm{C}$ with no contact between exudate and the meat sample. The weight 48 and $72 \mathrm{~h}$ after color parameter readings was determined in order to obtain the percentage weight losses. The weighing at $72 \mathrm{~h}$ was taken using the same sample.

Statistical analysis: the experimental design was completely randomized and the model was: $Y_{i j}=\mu+P_{i}+e_{i j}$ where $Y_{i j}$ is the $j^{\text {th }}$ observation at the $i^{\text {th }}$ position; $\mu$ the overall average; $P_{i}$ the effect of position $i$ and $e_{i j}$ the experimental error. The analysis of variance was done using PROC GLM in SAS (Statistics Analysis Systems Institute, version 9.2) and when significant $(p<0.05)$ the adjusted means were compared by Tukey test $(\alpha<0.05)$. The occurrence of lightness groups within each region was determined using PROC FORMAT and PROC FREQ from SAS, like the PEARSON correlation for all parameters.

\section{Assay 2}

Animals: twenty five commercial lineage pigs (Sus scrofa domesticus) from Pen Ar Lan genetics were used. The sampling was taken at the experimental abattoir that works under the State Inspection Service (SISP) regulated by Resolution n.24 (RAA 24; 01/08/1994) from the Brazilian Secretariat of Agriculture and Food Supply.

Plasma glycemia: blood samples were collected at slaughter when the animals were exsanguinated to determine plasma glycemia using a human blood glucose concentration checking device (Accu Chek $\left.{ }^{\circledR}\right)$. Animals were divided into two groups based on blood glucose levels: 12 animals with high levels, above $120 \mathrm{mg} \mathrm{dL}^{-1}$ $(134.5 \pm 5.3)$ and 13 with normal levels, below $80 \mathrm{mg}$ $\mathrm{dL}^{-1}(74.8 \pm 2.0)$. These levels may be associated with differences in the acidification of meat, producing impacts on color and drip loss (Choe et al., 2009).

Temperature: $2 \mathrm{~h}$ after slaughter the temperature of the carcasses was measured using a penetration thermometer.

Color: in assay 1 it was observed that color measures at several spots on the steak surface can be replaced by fewer measures at specific locations that are more highly correlated with drip loss. Therefore, for the second assay only three regions were used to measure color: lateral, intermediate and medial. Pork loin samples from right carcasses, between tenth and eleventh ribs, with $2.5 \mathrm{~cm}$ thickness were collected $24 \mathrm{~h}$ post-mortem and transferred to a meat laboratory for analysis. The color readings were made with the same calibrated device and standards from assay 1.

Exudate absorption by filter paper: the same procedure used in assay 1 was repeated in assay 2 with the 
difference that in assay 2 the filters that were put in the same regions (3) where the colors were measured instead of one filter for each steak.

Drip loss: the traditional method (Honikel and Hamm, 1994) was adapted to three regions on the steak surface where colors were also read. Cylinders were taken off in each anatomical region, using a leaker, weighed and placed inside the reticulated net bag wrapped in plastic bags. After $48 \mathrm{~h}$ the volume of drip was weighed to determine losses in each region. Following $24 \mathrm{~h}$, the same process in the same samples was carried out to determine drip loss at $72 \mathrm{~h}$.

Glucose exudate concentration: measured at the same time as drip loss determination at $48 \mathrm{~h}$ using a human blood glucose concentration checking device (Hamilton et al., 2003).

Statistical analysis: the experimental design was completely randomized in a two (levels of plasma glycemia) $\times$ three (anatomical regions on steak) factorial arrangement with 12 replicates for high and 13 for normal glycemia. The statistical model was $Y_{i j k l}=\mu+G_{i}+R_{j}+\left(G^{*} R\right)_{i j}+T_{k}+e_{i j k l}$, where $Y_{i j k}$ is the observation $k$ at $i^{\text {th }} G$ (glycemia) level and $j^{\text {th }} R$ (anatomical region); $\mu$ is the overall average; $G_{i}$ the effect from $\mathrm{G}$ (glycemia) factor at $i^{\text {th }}$ level; $\mathrm{R}_{\mathrm{j}}$ the effect from $\mathrm{R}$ (region) factor at $j^{\text {th }}$ level; $\left(G^{*} R\right)_{i j}$ the effect from interaction between $G$ factor at $i^{\text {th }}$ level and $R$ factor at $j^{\text {th }}$ level; $\mathrm{T}$ the effect from $\mathrm{T}$ (temperature) factor at $\mathrm{k}^{\text {th }}$ level (used as covariate in the statistical model); $e_{i j k l}$ is the experimental error. The variance analysis used the PROC GLM from SAS. When showing significance $p<$ $0.05)$ the adjusted means were compared by the Tukey test $(\alpha<0.05)$.

\section{Results and Discussion}

Assay 1: the study conducted with a reduced number of steaks (19) may account for the broad range for the average lightness $\left(\mathrm{L}^{*}\right)$ values (44.05 to 55.58), with $21 \%$ of the samples presenting readings above 50.79 which are above the threshold for pale and exudative pork (Warner et al., 1997). Furthermore, although $84 \%$ could be classified as reddish-pink pork with $\mathrm{L}^{*}$ readings between 42.00 and 50.00, there was also an indication that some of the samples within this color category might be classified as soft and exudative (RSE) when drip loss is taken into account (Figure 2). The occurrence of soft and exudative pork is well above $10 \%$, which would be expected in the industry. However, the sampling was random and greater sampling is needed to confirm this heterogeneity and high occurrence for pork with lightness problems.

The objective measures of color can be taken at many points on the steak surface. More readings combined with better choice of anatomical locations for these readings give a greater representativeness of the entire steak color (Mancini and Hunt, 2005). For this study, the correlations between the $\mathrm{L}^{*}$ values averaged from readings at all anatomical positions and steak drip loss had lower coefficients as compared to correlations that use $\mathrm{L}^{*}$ values taken at certain positions (Table 1).

The $\mathrm{L}^{*}$ averaged from readings at positions 5 and 6 (Figure 1) had the highest positive correlation coefficient with $\mathrm{L}^{*}$ values mean and median obtained from readings at all positions on steak (Figure 3). The mean $\mathrm{L}^{*}$ value obtained from readings at those same two positions had the highest determination coefficients with

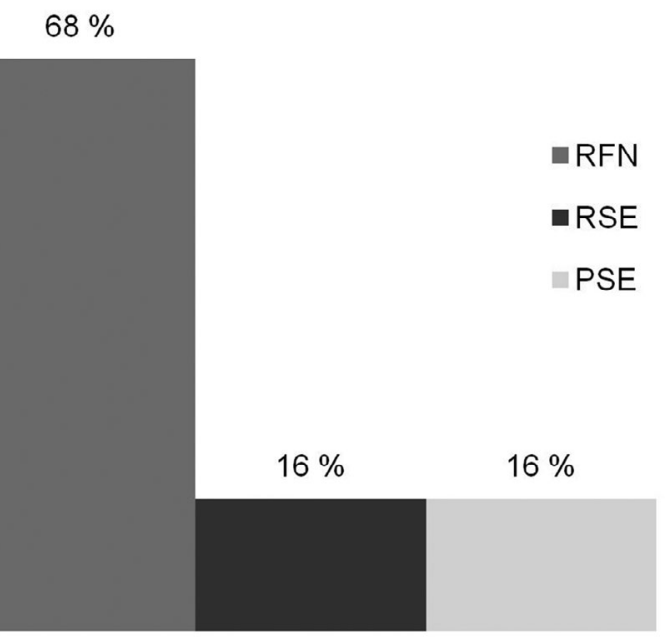

Figure 2-Occurrence of pork loin steaks sampled in a retail store at Piracicaba-SP according to the classification proposed by Warner et al. (1997): RFN - Reddish-pink, Firm, Non-exudative (L* 42-50, Drip Loss-DL $<5 \%$ ); RSE - Reddish-pink, Soft, Exudative (L* 42-50, $\mathrm{DL}>5 \%)$; PSE - Pale, Soft, Exudative $\left(\mathrm{L}^{*}>50, \mathrm{DL}>5 \%\right)$.

Table 1 - Correlations ${ }^{\dagger}$ between objective measures of lightness $\left(\mathrm{L}^{*}\right)$ mean in regions of the steak, drip loss (DL) and hue angle (Hue) in pork loin from a retail store.

\begin{tabular}{ccccc}
\hline & $\mathrm{L}^{*}$ mean & $\mathrm{DL} 48 \mathrm{~h}$ & $\mathrm{DL} 72 \mathrm{~h}$ & Hue \\
\hline $\mathrm{L}^{*}$ median & $0.98^{* *}$ & - & - & - \\
$\mathrm{DL} 48 \mathrm{~h}$ & $0.76^{*}$ & - & - & - \\
$\mathrm{DL} 72 \mathrm{~h}$ & $0.80^{* *}$ & $0.99^{* *}$ & - & - \\
Hue & $0.79^{* *}$ & $0.57^{*}$ & $0.66^{*}$ & - \\
$\mathrm{p} 2-\mathrm{p} 5^{\mathrm{a}}$ & $0.87^{* *}$ & $0.62^{*}$ & $0.66^{*}$ & $0.70^{*}$ \\
$\mathrm{p} 1-\mathrm{p} 4 \mathrm{r}$ & $0.76^{*}$ & $0.65^{*}$ & $0.71^{*}$ & $0.53^{*}$ \\
$\mathrm{p} 3-\mathrm{p} 6^{\mathrm{s}}$ & $0.91^{* *}$ & $0.65^{*}$ & $0.68^{*}$ & $0.75^{*}$ \\
$\mathrm{p} 1-\mathrm{p} 2^{\mathrm{t}}$ & $0.79^{* *}$ & $0.64^{*}$ & $0.68^{*}$ & $\mathrm{NS}^{+}$ \\
$\mathrm{p} 2-\mathrm{p} 3^{\mathrm{u}}$ & $0.83^{* *}$ & $0.53^{*}$ & $0.53^{*}$ & $0.73^{*}$ \\
$\mathrm{p} 4-\mathrm{p} 5^{\mathrm{v}}$ & $0.89^{* *}$ & $0.69^{*}$ & $0.74^{*}$ & $0.80^{* *}$ \\
$\mathrm{p} 5-\mathrm{p} 6^{*}$ & $0.95^{* *}$ & $0.80^{* *}$ & $0.83^{* *}$ & $0.71^{*}$ \\
\hline
\end{tabular}

†Significant ${ }^{*} p<0.05$ and ${ }^{* *} p<0.001 ;+$ NS: not significant $(p>0.05)$; lightness average of regions ap2-p5: 2 and 5 positions; rp1-p4: 1 and 4 positions; sp3-p6: 3 and 6 positions; tp1-p2: 1 and 2 positions; up2-up3: 2 and 3 positions; ${ }^{v p 4-p 5: ~} 4$ and 5 positions; ${ }^{p p 5-p 6: ~} 5$ and 6 positions. 
drip loss values in both 48 and $72 \mathrm{~h}$ determinations (Figure 4). These correlation coefficients were among the highest when position 5 and 6 were involved in the average $L^{*}$ readings. The high $L^{*}$ readings in this region represented by the two positions mentioned may be a result more closely related to exudation in pork loin. On the other hand, no differences were observed between the regions for average values for redness $\left(\mathrm{a}^{*}\right)$ or yellowness $\left(b^{*}\right)$.

Hue angle mean was the other color variable with significant correlation coefficients with $\mathrm{L}^{*}$ values readings and drip losses. Nonetheless, hue angles had lower correlation coefficients with drip losses at both times and with $\mathrm{L}^{*}$ mean compared to the $\mathrm{L}^{*}$ average with readings at regions represented by two positions that considered either position 5 or 6 (Table 1). The hue angle had the lowest or even no significant correlation coefficients with $\mathrm{L}^{*}$ readings when position 1 was included in the two position average.

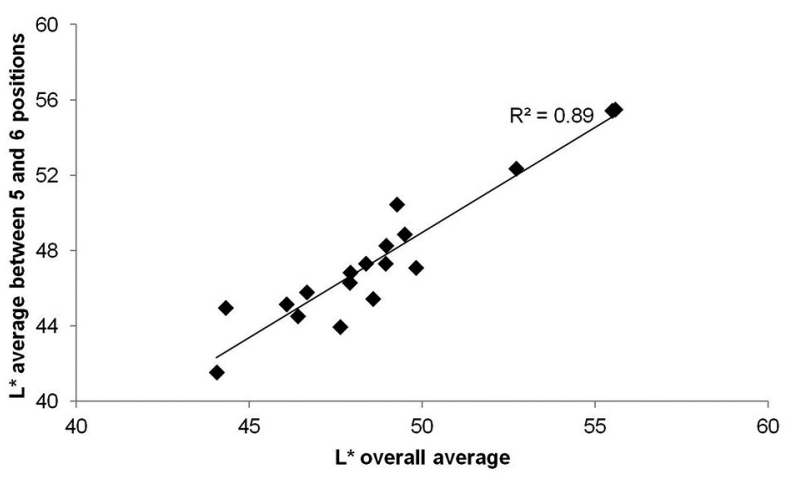

Figure 3 - Correlation between $L^{*}$ overall average and the $L^{*}$ average in positions 5 and 6 of steak loin sampled in a retail store.

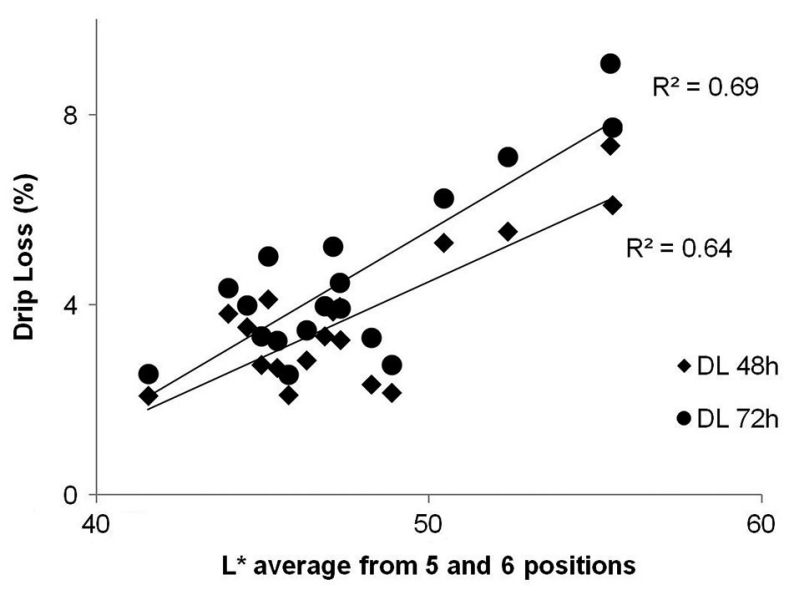

Figure 4 - Correlations between $\mathrm{L}^{*}$ average from 5 and 6 positions on the surface of pork loin with drip loss at 48 and $72 \mathrm{~h}$ from steaks sampled in a retail store.
The weaker correlations between hue angle and $\mathrm{L}^{*}$ readings are variable in response to the positions where the readings were taken (Table 2). Again, the average from position 5 and 6 had the highest correlation coefficients with $\mathrm{L}^{*}$ mean and drip losses. For some of the composed positions (two readings average) there was no significant correlation between hue angle and drip loss, especially for average readings where position 1 was included.

The highest positive correlation between $\mathrm{L}^{*}$ readings and hue angle averaged from positions 5 and 6 readings, as well as between those readings and the drip loss indicates that this location was lighter, less red and more yellow with increased drip loss. The behavior of $\mathrm{L}^{*}$ and hue angle changes had differences according to positions. This may be responsible for some visual non uniform color intensity, which will be called two toning. The visual pink color intensity is high and negatively correlated with $\mathrm{L}^{*}$ and the hue angle (Brewer et al., 2001).

Chroma parameter and exudate absorption by filter paper was not related to drip losses either in terms of time or regions. High positive correlation between drip losses at different hours shows that at 48 hours it is possible to predict the losses that will occur at $72 \mathrm{~h}$ (Figure 5). Although there was no difference for determined color variables at several positions (Table 3), the frequency for high lightness values occurrence observed in the average from positions 5 and 6 fits the frequency for pale and exudative meat (Table 4). Therefore, even though there was lower occurrence for higher $\mathrm{L}^{*}$ values in the ventro-lateral region for this study, when it happened it was associated with higher drip losses. On the other hand, when higher $\mathrm{L}^{*}$ values appear in other anatomical positions, like in dorso-medial, this association is not seen.

Partial considerations: Lightness $\left(\mathrm{L}^{*}\right)$ reading in the ventro-lateral region (average from positions 5 and 6 readings) of pork loin reflects the $\mathrm{L}^{*}$ mean values from all positions in steak surface. The drip losses at different times persist in steady steps up to $72 \mathrm{~h}$, and can be esti-

Table 2 - Correlations ${ }^{\dagger}$ between hue angle (Hue) in regions of the steak, lightness mean $\left(\mathrm{L}^{*}\right)$ and drip loss $(\mathrm{DL})$ at 48 and $72 \mathrm{~h}$ in the pork loin from a retail store.

\begin{tabular}{|c|c|c|c|c|}
\hline & & $\mathrm{L}^{*}$ mean & DL 48h & DL 72h \\
\hline \multirow{7}{*}{ Hue } & p2-p5 ${ }^{q}$ & $0.66^{*}$ & $0.52^{*}$ & $0.57^{*}$ \\
\hline & $\mathrm{p} 1-\mathrm{p} 4^{r}$ & $0.51^{*}$ & NS+ & $0.56^{*}$ \\
\hline & p3-p6 s & $0.71^{* *}$ & $0.47^{*}$ & NS \\
\hline & $\mathrm{p} 1-\mathrm{p} 2^{\mathrm{t}}$ & $0.48^{*}$ & NS & $0.48^{*}$ \\
\hline & p2-p3u & $0.56^{*}$ & NS & NS \\
\hline & p4-p5 & $0.55^{*}$ & NS & $0.55^{*}$ \\
\hline & p5-p6x & $0.77^{* *}$ & $0.69^{*}$ & $0.72^{* *}$ \\
\hline
\end{tabular}

${ }^{\dagger}$ Significant ${ }^{*} p<0.05$ and ${ }^{* *} p<0.001 ;+$ NS: non-significant $(p>0.05)$; Hue average of regions ${ }^{q} p 2-p 5: 2$ and 5 positions; ${ }^{\prime} p 1-p 4: 1$ and 4 positions; sp3-p6: 3 and 6 positions; tp1-p2: 1 and 2 positions; " $\mathrm{pp} 2-\mathrm{p} 3: 2$ and 3 positions; vp4-p5: 4 and 5 positions; ${ }^{x p 5-p 6: ~ a t ~ p o s i t i o n s ~} 5$ and 6. 
Table 3 - Lightness $\left(L^{*}\right)$, redness $\left(a^{*}\right)$, yellowness $\left(b^{*}\right)$, Hue angle and Chroma in anatomical position of the pork loin steaks from a retail store.

\begin{tabular}{lccccc}
\hline Position & $\mathrm{L}^{*}$ & $\mathrm{a}^{*}$ & $\mathrm{~b}^{*}$ & Hue & Chroma \\
\hline 1 & $48.07(1.02) \mathrm{i}$ & $8.42(0.38)$ & $2.82(0.22)$ & $18.32(1.07)$ & $8.90(0.41)$ \\
2 & $47.15(0.99)$ & $9.03(0.59)$ & $3.18(0.30)$ & $18.97(1.40)$ & $9.61(0.62)$ \\
3 & $49.06(1.07)$ & $9.01(0.63)$ & $3.54(0.45)$ & $20.25(1.74)$ & $9.75(0.73)$ \\
4 & $48.33(1.19)$ & $8.40(0.36)$ & $3.04(0.37)$ & $18.89(1.67)$ & $9.00(0.45)$ \\
5 & $50.95(0.84)$ & $7.61(0.40)$ & $3.36(0.27)$ & $23.48(1.22)$ & $8.35(0.45)$ \\
6 & $49.46(0.84)$ & $8.44(0.39)$ & $3.42(0.21)$ & $22.40(1.09)$ & $9.15(0.45)$ \\
Significancy & $\mathrm{ns}$ & $\mathrm{ns}$ & $\mathrm{ns}$ & $\mathrm{ns}$ & $\mathrm{ns}$ \\
\hline
\end{tabular}

ivalues in parentheses: standard error; ${ }^{+} n s:$ not significant $(p>0.05)$.

Table 4 - Count and frequency of lightness $\left(L^{*}\right)$ ranges within regions in pork loin steaks from a retail store.

\begin{tabular}{|c|c|c|c|c|c|c|c|}
\hline \multicolumn{2}{|l|}{$\mathrm{L}^{*}$} & \multicolumn{6}{|c|}{ p2-p5 $p 1-p 4^{r} p 3-p 6^{s} p 1-p 2^{t} p 2-p 3^{u} p 4-p 5^{v} p 5-p 6^{x}$} \\
\hline \multirow{2}{*}{$>50$} & Count & $8 \quad 7$ & 5 & 9 & 10 & 5 & 4 \\
\hline & Frequency (\%) & 42.1136 .84 & 26.32 & 47.37 & 52.63 & 26.32 & 22.22 \\
\hline \multirow{2}{*}{$42-50$} & & $11 \quad 12$ & 14 & 10 & 9 & 14 & 14 \\
\hline & Frequency (\%) & 57.8963 .16 & 73.68 & 52.63 & 47.37 & 73.68 & 77.78 \\
\hline
\end{tabular}

Lightness values averaged at regions ${ }^{\mathrm{p}} \mathrm{p} 2 \mathrm{-P5}$ : positions 2 and 5; ' $\mathrm{p} 1-\mathrm{p} 4$ : positions 1 and 4; sp3-P6: positions 3 and 6; tp1-p2: positions 1 and 2; " $p 2-p 3$ : positions 2 and 3; vp4-p5: positions 4 and 5; ${ }^{p} \mathrm{p} 5$-p6: positions 5 and 6.

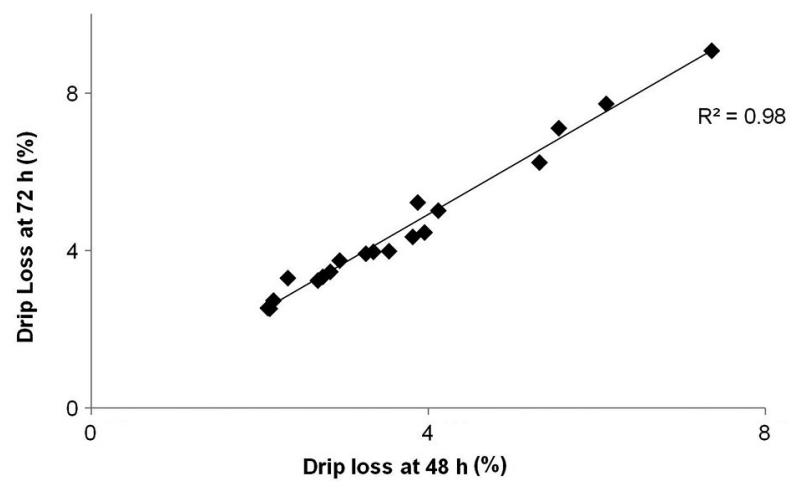

Figure 5 - Correlation between drip loss at 48 and $72 \mathrm{~h}$ of pork loin steaks sampled in a retail store.

mated for $\mathrm{L}^{*}$ mean, median and ventro-lateral readings. Chroma and exudate absorption by filter paper were not correlated with drip losses. The regions in the same steak had potentially different color and drip loss even under the same cooling conditions.

Assay 2: no interaction was observed between glycemia and anatomical regions in steak pork loin. The $\mathrm{pH}$ values measure at $24 \mathrm{~h}$ post-mortem for the high glycemic group and for the normal one were: $5.55 \pm 0.04$ vs 5.65 \pm 0.03 , respectively. The drip losses at $48 \mathrm{~h}$ were different $(p<0.01)$ between the groups of high and normal plasma glucose, with higher losses observed for the former group as compared to the latter $(9.0 \pm 0.4$ vs $8.0 \pm$

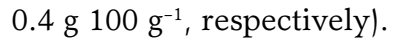

The evaluation for drip loss at $72 \mathrm{~h}$ also showed differences $(p<0.05)$ between the glycemic groups, and it corroborates the results from assay 1 for steady step behavior between 48 and $72 \mathrm{~h}$. The group that had greater plasma glucose continued to present higher losses compared with normal plasma glucose $(12.0 \pm 1.0 \mathrm{vs}$

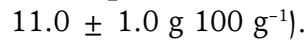

The results for $\mathrm{pH}$ and drip losses could classify both groups into PSE or RSE categories, according to the Warner et al. (1997) classification, for showing $\mathrm{pH}$ values lower than 6 and drip losses above $5 \%$. The inadequate cooling condition from the technical point of view, with carcasses exposed to ambient temperature for $4 \mathrm{~h}$ after slaughter caused greater losses of water. Temperature was a significant factor $(p<0.05)$ in determining drip loss, $\mathrm{L}^{*}$ parameters and glucose exudate concentration. The high glycemic group had an average temperature at $2 \mathrm{~h}$ of $29.75 \pm 0.93{ }^{\circ} \mathrm{C}$ versus $28.08 \pm 0.89{ }^{\circ} \mathrm{C}$ for the normal glycemic group. The adequate temperature fall through accelerated chilling for pig carcasses is a technique that can be used to improve pork loin quality, by acting to reduce drip losses (Springer et al., 2003). Nonetheless, this conditioning may have provided the right stage for favoring different drip losses between the groups. These differences in drip losses, in modest amounts, were reported before only with much greater plasma glucose differences and an extremely high plasma glucose concentration (Choe et al., 2009).

The high drip losses and differences in surface color were associated with low $\mathrm{pH}$ values observed, as expected. These results corroborate the idea of the conditioning being determinant to that observed association, since the lowest $\mathrm{pH}$ values were linked to the highest drip losses, with higher correlation until 180 min after slaughter (Kapper et al., 2014). While this association between $\mathrm{pH}$ and drip losses was previously considered as being related only to high initial levels of glycogen (Bendall and Swatland, 1988), the complex properties of the muscle metabolism, including the mitochondrial contribution, may be more related to the $\mathrm{pH}$ decline process than the glycogen content alone (Scheffler et al., 2013). The changing in steak color surface at different anatomical positions may contribute to explaining the properties that will define meat color and water holding capacity.

The drip losses were also different $(p<0.05)$ at $48 \mathrm{~h}$ among anatomical regions, with greater values in the intermediate region from the high glycemic group as compared to the medial region from the normal glycemic group (Table 5). The drip loss at intermediate and 
lateral regions was not different $(p=0.54)$ as well as the lateral and medial regions $(p=0.21)$. Drip loss at $72 \mathrm{~h}$ was not different $(p \geq 0.07)$ among regions (Table 5).

The exudate absorption by filter paper differ $(p$ $<0.01$ ) between the glycemic groups, being greater for high plasma glucose animals than for the normal glyce-

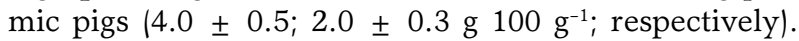
There were no differences for exudate absorption by filter paper among steak surface regions (Table 5). Exudate glucose concentration did not differ $(p=0.39)$ between the high and normal glycemic groups. These results do not corroborate with a direct impact of plasma glucose availability on glucose exudate concentration by modification of the muscle glycolytic potential, which is due to the glucose, glycogen and lactate content (Monin and Sellier, 1985). High and positive correlation between glucose exudate concentration and glycolytic potential postmortem has been reported, which in turn was negatively correlated with meat quality (Hamilton et al., 2003).

On the other hand, glucose exudate concentration was different among regions $(p<0.05)$. The lateral region presented greater glucose exudate concentration than the medial $(290.92 \pm 20.93$ vs $207.09 \pm 21.44 \mathrm{mg}$ $\mathrm{dL}^{-1}$, respectively), but was not different $(p=0.71)$ from the intermediate $\left(265.46 \pm 21.27 \mathrm{mg} \mathrm{dL}^{-1}\right)$. The latter had the same glucose concentration observed in the medial region $(p=0.15)$.

Color variables were not different among plasma glucose groups, but differences among regions were found. The $\mathrm{L}^{*}$ values in the intermediate region from the high glycemic group are higher than those at the medial region from the normal glycemic group (Table 6). When the lateral and medial regions were compared, the lightness was not different $(p=0.30)$. For similar glycemic levels (135 vs $88 \mathrm{mg} \mathrm{dL}^{-1}$ ) no differences were found between lightness and muscle fiber area composition for type IIb, while higher glycemic level $\left(231 \mathrm{mg} \mathrm{dL}^{-1}\right)$ showed greater values for these characteristics (Choe et al., 2009).

Lightness and exudate absorption by filter paper points to a marked effect of glycemic level on the surface steak region color and exudation. The greater drip loss associated with high $\mathrm{L}^{*}$ readings for the intermedi- ate region from high glycemic level may be a reflection of different glycolytic potential dictated by a fiber profile, which differs in its ability to store glycogen after acute stress. The fast-twitch white type of muscle rapidly stores glycogen from lactate after exercise (McLane and Holloszy, 1978). Moreover, those fibers have higher glycogen concentration after rest and they are metabolically better equipped for anaerobic glycogen utilization and faster glycolysis than slow twitch type I fibers (Klont et al., 1998). On the other hand, slow twitch fibers are better equipped to respond to insulin (Song et al., 1999) in order to increase glucose uptake and disposal resulting in glycogen synthesis at higher rates (James et al., 1985), and are, hence, candidates that can alter the glycolytic potential. These differential responses related to fiber type profile may be the reason for the importance of the distribution of glycogen within the muscle and not overall concentration from muscle in defining meat quality (Hambrecht et al., 2005). Also recent review suggests that mitochondria, besides differences in content between fibers types, play an important role in the extent of $\mathrm{pH}$ decline, with ultrastructural changes observed in PSE (Hudson, 2012).

The $a^{*}$ value in the intermediate region $16.68 \pm$ $0.25)$ was lower $(p<0.02)$ than those observed for medial $(7.68 \pm 0.24)$ and lateral $(7.69 \pm 0.27)$ regions. Those differences were associated with differences between the intermediate region of the high glycemic group and lateral/medial regions of the normal group (Table 6).

Although the results for $\mathrm{L}^{*}$ and $\mathrm{a}^{*}$ were similar for both plasma glucose groups, they showed different behavior within anatomical regions and their relationship with water holding capacity and glucose exudate concentration. The intermediate region contributes negatively to the overall perception of color, because both $\mathrm{L}^{*}$ (higher) and $\mathrm{a}^{*}$ (lower) values corroborate this visual paleness typical for PSE pork. When greater lightness values associates with decreased redness $\left(\mathrm{a}^{*}\right)$ there is a perception of pale and lighter areas on the pork loin surface (Hammelman et al., 2003). Furthermore, visual redness has high positive correlation to $\mathrm{a}^{*}$ values $(\mathrm{Zhu}$ and Brewer, 1999). On the other hand, there was no significant correlation between $\mathrm{a}^{*}$ value and visual pink

Table 5 - Drip losses (DL), exudate absorbed by filter paper (Filter) and exudate glucose concentration (GE) according to three anatomical regions evaluated on same steak pork loin into two groups of plasma glucose at slaughter in an experimental abattoir.

\begin{tabular}{|c|c|c|c|c|c|}
\hline & Region & DL 48h & $\mathrm{DL} 72 \mathrm{~h}$ & Filter & GE \\
\hline & & & $\left.0 g^{-1}\right)$ & - & $\mathrm{mg} \mathrm{dL}^{-1}$ \\
\hline \multirow{3}{*}{$\mathrm{Highr}^{r}$} & Lateral & $9.0^{\mathrm{ab}}(0.6)^{\dagger}$ & $12.0(0.8)$ & $5.0(1.1)$ & $262.92(27.96)$ \\
\hline & Intermed. & $11.0^{a}(0.8)$ & $13.0(0.8)$ & $5.0(0.8)$ & $252.42(20.48)$ \\
\hline & Medial & $8.0^{\mathrm{ab}}(0.8)$ & $11.0(1.0)$ & $2.0(0.5)$ & $196.36(26.88)$ \\
\hline \multirow{3}{*}{ Normals $^{\mathrm{s}}$} & Lateral & $9.0^{\mathrm{ab}}(0.6)$ & $11.0(0.9)$ & $3.0(0.6)$ & $316.77(30.11)$ \\
\hline & Intermed. & $9.0^{\mathrm{ab}}(0.8)$ & $11.0(0.9)$ & $2.0(0.4)$ & $278.50(37.97)$ \\
\hline & Medial & $7.0^{\mathrm{b}}(0.9)$ & $9.0(0.9)$ & $3.0(0.8)$ & $217.82(34.33)$ \\
\hline \multicolumn{2}{|c|}{ Significancy } & * & $\mathrm{ns}^{+}$ & ns & $\mathrm{ns}$ \\
\hline
\end{tabular}

†Values in parentheses: standard error; 'High: blood glucose above $120 \mathrm{mg} \mathrm{dL}^{-1}(134.5 \pm 5.3)$; sNormal: blood glucose below $80 \mathrm{mg} \mathrm{dL}^{-1}(74.8 \pm 2.0)$; a,bMeans followed by common letter are not different; ${ }^{*} p<0.05$; ${ }^{n}$ s: not significant $(p>0.05)$. 
Table 6 - Color variables $L^{*}, a^{*}, b^{*}$, Hue angle and Chroma according to three anatomical regions evaluated on same steak pork loin into two groups of plasma glucose at slaughter in an experimental abattoir.

\begin{tabular}{|c|c|c|c|c|c|c|}
\hline & & $L^{* u}$ & $a^{* v}$ & $b^{\star x}$ & Hue $^{w}$ & Chroma $^{2}$ \\
\hline & Lateral & $52.81^{\text {ab }}(1.65)^{\dagger}$ & $7.46^{\text {ab }}(0.35)$ & $3.53(0.48)$ & $24.03(2.25)$ & $8.32(0.51)$ \\
\hline \multirow[t]{3}{*}{$\mathrm{High}^{\#}$} & Interm. & $56.15^{\mathrm{a}}(1.20)$ & $6.39^{b}(0.36)$ & $3.32(0.32)$ & 26.95 (1.19) & $7.22(0.45)$ \\
\hline & Medial & $50.02^{\mathrm{b}}(1.01)$ & 7.44 ab (0.28) & $2.97(0.32)$ & $21.20(1.28)$ & $8.03(0.38)$ \\
\hline & Lateral & $52.81^{\mathrm{ab}}(1.05)$ & $7.90^{\mathrm{a}}(0.40)$ & $3.82(0.33)$ & $25.43(1.10)$ & 8.79 (0.49) \\
\hline \multirow[t]{2}{*}{ Normal $^{+}$} & Interm. & $55.56^{\mathrm{ab}}(1.55)$ & $6.95^{\mathrm{ab}}(0.35)$ & $3.64(0.35)$ & $27.13(1.62)$ & $7.88(0.44)$ \\
\hline & Medial & $51.81^{\mathrm{b}}(1.65)$ & $7.91^{\mathrm{a}}(0.39)$ & $3.47(0.41)$ & $22.83(1.72)$ & $8.69(0.50)$ \\
\hline
\end{tabular}

†Values in parentheses: standard error; "L ${ }^{*}$ : lightness scale of 0 (black) to 100 (white); ${ }^{*}{ }^{*}$ : redness, negative numbers color $=$ green, positive numbers $=$ color red;

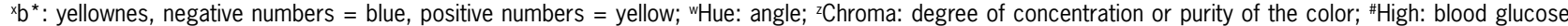
above $120 \mathrm{mg} \mathrm{dL}^{-1}(134.5 \pm 5.3)$; +Normal: blood glucose below $80 \mathrm{mg} \mathrm{dL}{ }^{-1}(74.8 \pm 2.0)$; a,bMeans followed by common letter are not different; * ${ }^{*} p<0.05$; * $p$ $<0.07 ;{ }^{+}$ns: not significant $(p>0.07)$.

color intensity when color was measured in pork loin using the Minolta illuminant $\mathrm{C}$ settings (Brewer et al., 2001). The $b^{*}(3.47 \pm 0.48)$, Hue angle (24.62 \pm 2.25$)$ and Chroma $(8.17 \pm 0.51)$ were not different among either groups or regions (Table 6).

Partial considerations: High plasma glucose concentration at slaughter may contribute to increased drip loss. Paleness in intermediate region linked to non-uniform pork loin color is associated with high drip loss and suggests differences in the glycolytic process among surface regions. The higher glucose exudate concentration in the intermediate and lateral regions corroborates with this hypothesis.

\section{Conclusions}

The $L^{*}$ readings at the ventro-lateral region may potentially be the point at which excessive drip loss and paleness can be predicted. Those readings associated with hue angle as compared to the dorso-medial position readings may help to identify two-toning pork loin. Animals with high plasma glucose concentration at slaughter are susceptible to problems with water holding capacity.

\section{Acknowledgements}

To National Research Council - CNPq (Brazilian National Council for Scientific and Technological Development) for the scholarship. To Dr. Saulo da Luz e Silva for assistance in the analytical procedures and Elso Carlos Terciotti for sample collection.

\section{References}

Bendall, J.R.; Swatland, H.J. 1988. A Review of the relationships of $\mathrm{pH}$ with physical aspects of pork quality. Meat Science 24: 85-126.

Brewer, M.S.; Zhu, L.G.; Bidner, B.; Meisinger, D.J.; McKeith, F.K. 2001. Measuring pork color: effects of bloom time, muscle, $\mathrm{pH}$ and relationship to instrumental parameters. Meat Science 57: $169-176$.
Cannon, J.E.; Morgan, J.B.; McKeith, F.K.; Smith, G.C.; Sonka, S.; Heavner, J.; Meeker, D.L. 1996. Pork chain quality audit survey: quantification of pork quality characteristics. Journal of Muscle Foods 7: 29-44.

Choe, J.H.; Choi, Y.M.; Lee, S.H.; Nam, Y.J.; Jung, Y.C.; Park, H.C.; Kim, Y.Y.; Kim, B.C. 2009. The relation of blood glucose level to muscle fiber characteristics and pork quality traits. Meat Science 83: 62-67.

Fonseca, S.; Wilson, I.J.; Horgan, G.W.; Maltin, C.A. 2003. Slow fiber cluster pattern in pig longissimus thoracis muscle: Implication for myogenesis. Journal of Animal Science 81: 973-983.

Hambrecht, E.; Eissen, J.J.; Newman, D.J.; Smits, C.H.M.; Verstegen, M.W.A.; Den Hartog, L.A. 2005. Preslaughter handling effects on pork quality and glycolytic potential in two muscles differing in fiber type composition. Journal of Animal Science 83: 900-907.

Hamilton, D.N.; Miller, K.D.; Ellis, M.; McKeith, F.K.; Wilson, E.R. 2003. Relationships between longissimus glycolytic potential and swine growth performance, carcass traits, and pork quality. Journal of Animal Science 81: 2206-2212.

Hammelman, J.E.; Bowker, B.C.; Grant, A.L.; Forrest, J.C.; Schinckel, A.P.; Gerrard, D.E. 2003. Early postmortem electrical stimulation simulates PSE pork development. Meat Science 63: 69-77.

Honikel, K.O.; Hamm, R. 1994. Quality attributes and their measurement in meat, poultry and fish products. p. 125159. In: Pearson, A.M.; Dutson, T.R., eds. Advances in meat research. Beltsville, MD, USA.

Hudson, N.J. 2012. Mitochondrial treason: a driver of $\mathrm{pH}$ decline rate in post-mortem muscle? Animal Production Science 52: 1107-1110.

James, D.E.; Jenkis, A.B.; Kraegen, E.W. 1985. Heterogeneity of insulin action in individual muscles in vivo: euglycemic clamp studies in rats. American Journal of Physiology-Endocrinology and Metabolism 248: E567-E574.

Kapper, C.; Walukonis, C.J.; Scheffler, T.I.; Scheffler, J.M.; Don, C.; Morgan, M.T.; Forrest, J.C.; Gerrard, D.E. 2014. Moisture absorption early postmortem predicts ultimate drip loss in fresh pork. Meat Science 96: 971-976.

Kauffman, R.G.; Van Laack, R.L.; Russel, R.L.; Pospiech, E.; Cornelius, C.A.; Suckow, C.E.; Greaser, M.L. 1998. Can pale, soft and exudative pork be prevented by postmortem sodium bicarbonate injection? Journal of Animal Science 76: 30103015. 
Klont, R.E.; Brocks, L.; Eikelenboom, G. 1998. Muscle fibre type and meat quality. Meat Science 49: S 219-S229.

Mancini, R.A.; Hunt, M.C. 2005. Current research in meat color. Meat Science 71: 100-121.

McLane, J.A.; Holloszy, J.O. 1979. Glycogen synthesis from lactate in three types of skeletal muscle. Journal of Biological Chemistry 254: 6548-6553.

Monin, G.; Sellier, P. 1985. Pork of low technological quality with a normal rate of muscle $\mathrm{pH}$ fall in the immediate post-mortem period: the case of the Hampshire breed. Meat Science 13: 4963.

Scheffler, T.I.; Scheffler, J.M.; Kasten, S.C.; Sosnick, A.A.; Gerrard, D.E. 2013. High glycolytic potential does not predict low ultimate $\mathrm{pH}$ in pork. Meat Science 95: 85-91.
Song, X.M.; Ryder, J.W.; Kawano, Y.; Chibalin, A.V.; Krook, A.; Zierath, J.R. 1999. Muscle fiber type specificity in insulin signal transduction. American Journal of Physiology-Regulatory Integrative and Comparative Physiology 277: R1690-R1696.

Springer, M.P.; Carr, M.A.; Ramsey, C.B.; Miller, M.F. 2003. Accelerated chilling of carcasses to improve pork quality. Journal of Animal Science 81: 1464-1472.

Warner, R.D.; Kauffman, R.G.; Greaser, M.L. 1997. Muscle protein changes post mortem in relation to pork quality traits. Meat Science 45: 339-352.

Zhu, L.G.; Brewer, M.S. 1999. Relationship between instrumental and visual color in a raw, fresh beef and chicken model system. Journal of Muscle Foods 10: 131-146. 